\title{
Testicular volume: correlation of ultrasonography, orchidometer and caliper measurements in children
}

\author{
Lofty-John C. Anyanwu ${ }^{1,2^{*}} \mathbb{0}$, Oludayo A. Sowande ${ }^{1}$, Christianah M. Asaleye ${ }^{3}$, Mohammed K. Saleh4, \\ Aminu M. Mohammad ${ }^{2}$, Mayomi Onuwaje ${ }^{3}$, Timothy A. Olajide ${ }^{1}$, Ademola O. Talabi ${ }^{1}$, Jerome B. E. Elusiyan ${ }^{5}$ \\ and Olusanya Adejuyigbe ${ }^{1}$
}

\begin{abstract}
Background: Testicular size assessment is an important and initial technique for the evaluation of gonadal function. Our study aims to determine the correlation between paediatric testicular volumes measured with the orchidometer, high-resolution ultrasonography (US) and intra-operative measurements using calipers.

Results: This is a prospective observational study of 127 boys presenting to our institution with non-emergent scrotal conditions between January 2007 and October 2008. Volume estimates of both testes were measured using the Prader orchidometer. The patient was then sent to a radiologist who measured the testicular volumes using US, being blinded to the orchidometer estimates. At surgery, the testicular dimensions on the side of the pathology were obtained with a vernier caliper. The testicular volumes by US and caliper were calculated using the formula $0.71 \times$ Length $\times$ Width $\times$ Height. The relationship between the measured volumes was determined using Pearson's correlation statistic and Student's $t$ test. The level of significance for all analysis was set at $p<0.05$. Their ages ranged from 18 days to 13 years (median 3 years). There was significant correlation between testicular volumes (for both sides, i.e. right and left) measured with the orchidometer and US $(r=0.544 ; 0.537, p<0.001)$, significant correlation between testicular volumes measured with the orchidometer and caliper $(r=0.537 ; 0.638, p<0.001)$ and also significant correlation between volumes measured by US and caliper $(r=0.382 ; 0.829, p<0.01)$.
\end{abstract}

Conclusion: Prader orchidometer testicular volume estimates correlate significantly with US estimates in children. In resource-constrained settings, it could be used for an accurate and quick testicular volume assessment.

Keywords: Testis, Ultrasonography, Orchidometer, Caliper, Children

\section{Background}

In children, adolescents and adults, the measurement of testicular volume is very important in the initial assessment of gonadal function, since it correlates well with various indices of testicular function [1-5]. It has been shown that about $70-80 \%$ of testicular parenchyma consists of seminiferous tubules [4]. Thus, an accurate

\footnotetext{
*Correspondence: loftyjohnc@yahoo.com

2 Present Address: Paediatric Surgery Unit, Department of Surgery, Aminu

Kano Teaching Hospital and Bayero University, Kano, Nigeria

Full list of author information is available at the end of the article
}

determination of the volume of the testis will assist in the evaluation of patients suffering from a number of developmental, growth and functional abnormalities of the testis such as Klinefelter syndrome (small testis), fragile $\mathrm{X}$-syndrome (macro-orchidism), undescended testis, varicocele and testicular torsion [6-11].

Various methods have been used in the evaluation of testicular volume. Some of these are orchidometer, visual comparison, calipers, ruler and ultrasonography $[1,4,12$, 13]. The Prader orchidometer is commonly employed in the clinical evaluation of testicular volume, given that it is relatively easier to use and is less time-consuming 
than ultrasonography (US) $[14,15]$. There are many who believe that US gives the most accurate in situ estimation of the volume of the testis $[12,13]$. Testicular volume measurements by US are calculated from measured parameters $[1,4,12,13]$. In order to obtain the true testicular volume, it has to be surgically removed and the epididymis and other peritesticular tissues excised, after which it is then immersed in a water containing measuring cylinder to obtain its volume by water displacement (Archimedes principle) [11, 13, 16]. This method is not used for in situ testicular volume measurement.

Many workers believe that the testicular volume measurements with US correlate closely with orchidometer estimates $[4,15]$. Some, however, have shown that the orchidometer tended to overestimate the testicular volume, especially in small testes $[12,13]$. This present study aims to determine the correlation between testicular volume measured with the Prader orchidometer, highresolution ultrasonography and intra-operative measurements using calipers in children.

\section{Methods}

This is a prospective observational study of 127 boys presenting to our hospital with non-emergent scrotal conditions between January 2007 and October 2008. Ethical approval was obtained from the research and ethics committee of the hospital. Informed consent was obtained from parents and caregivers of recruited children and assent from children older than 7 years.

After taking a detailed clinical history, physical examination of the scrotum was done in a warm room at the paediatric surgery outpatient clinic. Volume estimates of both testes were measured using the Prader orchidometer.

All the subjects had ultrasonography (US) of their testes while supine and relaxed. The scans were done in the radiology department of our hospital and were interpreted by a consultant radiologist. A high-frequency transducer (7.5MHZ) and a Siemens diagnostic ultrasound machine [system 4900531-LH300, catalogue number 490056-LV300, serial number (BBE2355)] were used for all the scans. The US report gave the testicular parameters measured, i.e. ( $\mathrm{L}, \mathrm{H}, \mathrm{W})$, where ' $\mathrm{L}$ ' is the length of the testis from the superior to the inferior pole; ' $\mathrm{H}$ ' is the height of the testis or its maximum dimension in the antero-posterior or sagittal plane; and ' $\mathrm{W}$ ' is the width of the testis or its maximum dimension in the transverse or coronal plane [17]. These measurements were used to calculate the testicular volume.

Intra-operatively under general anaesthesia, measurements of the testicular parameters $(\mathrm{L}, \mathrm{H}, \mathrm{W})$ were taken on the side of the pathology. The measurements were taken under vision by opening the tunica vaginalis and delivering the testis into the wound. Vernier calipers were used to obtain the intra-operative measurements which were used to calculate the testicular volume. All volume calculations were carried out using the empirical formula of Lambert (Length $\times$ Width $\times$ Height $\times 0.71)$ earlier described by other workers [13].

Data were entered into a proforma prepared for the study. Analysis was performed using SPSS version 15.0 for windows (SPSS Inc, Chicago IL). Descriptive statistics were computed for continuous variables, while proportions were used for categorical characteristics of the study subjects. Pearson's correlation statistic and the Student's $t$ test were used to test for relationships between the measured volumes. The level of significance for all analyses was set at $p<0.05$.

\section{Results}

One hundred and twenty-seven participants were recruited into the study. Their ages ranged from 18 days to 13 years (median 3 years). Of the 127 patients in this study, $63(49.6 \%)$ had right hemiscrotal pathology, 45 (35.4\%) had a left-sided pathology, while 19 (15\%) of them had a bilateral scrotal condition. In $45.9 \%$ (67/146) of the conditions, the diagnosis was an inguinoscrotal hernia, congenital hydrocoele in $42.5 \%$ (62/146), undescended testis in $8.2 \%(12 / 146)$, symptomatic retractile testis in $2.1 \%(3 / 146)$, recurrent testicular torsion in $0.7 \%$ $(1 / 146)$ and varicocoele in $0.7 \%(1 / 146)$.

In all, 254 testicles were examined in the 127 boys. Two testes (one right and one left) were not palpable and thus were not assessed with the orchidometer. Ultrasonography (US) report was available for 116 right testes and for 119 left testes. Intra-operative caliper measurements were taken in 75 right and 55 left testes. Table 1 depicts the mean testicular volumes, and the results of the correlational analysis for various volumes measured (which

Table 1 Testicular volume measurements by side and method

\begin{tabular}{|c|c|c|c|c|c|c|}
\hline \multirow[t]{2}{*}{ Side } & \multicolumn{2}{|c|}{ Orchidometer (mls) } & \multicolumn{2}{|c|}{ Ultrasonography (mls) } & \multicolumn{2}{|c|}{ Caliper (mls) } \\
\hline & $n$ & Mean (SD) & $n$ & Mean (SD) & $n$ & Mean (SD) \\
\hline Right & 126 & $1.83(0.94)$ & 116 & $1.22(1.18)$ & 75 & $0.40(0.40)$ \\
\hline Left & 126 & $1.81(1.09)$ & 119 & $1.16(0.98)$ & 55 & $0.45(0.56)$ \\
\hline
\end{tabular}


showed a significant correlation between the volume estimates) are shown in Table 2 (also Figs. 1 and 2).

The orchidometer estimates of testicular volume were significantly larger than the volume estimates obtained using US on the right $(t=6.636 ; p<0.001)$ and on the left $(t=7.173 ; p<0.001)$ (Table 1$)$. The mean testicular volume measured with the orchidometer was higher on

Table 2 Correlation matrix of the methods of testicular volume measurements by side

\begin{tabular}{lllll}
\hline Side & Volume & RTVO & RTVC & RTVU \\
\hline Right & RTVO & 1 & $0.537^{*}$ & $0.544^{*}$ \\
& RTVC & & 1 & $0.382^{* *}$ \\
\multirow{3}{*}{ Left } & RTVU & & & 1 \\
& Volume & LTVO & LTVC & LTVU \\
& LTVO & 1 & $0.638^{*}$ & $0.537^{*}$ \\
& LTVC & & 1 & $0.829^{*}$ \\
& LTVU & & & 1 \\
\hline
\end{tabular}

$R T V O$ right testicular volume by orchidometer, RTVC right testicular volume by caliper, RTVU right testicular volume by ultrasonography, LTVO left testicular volume by orchidometer, LTVC left testicular volume by calliper, LTVU left testicular volume by ultrasonography

${ }^{*} p<001 ;{ }^{* *} p<01$ the right $(1.83 \mathrm{mls})$ than on the left $(1.81 \mathrm{mls})$, though this was not statistically significant $(t=0.280 ; p=0.780)$. Also the mean testicular volume measured with the US was higher on the right $(1.22 \mathrm{mls})$ than the left $(1.16 \mathrm{mls})$, and this also was not statistically significant $(t=0.571$; $p=0.569)$.

\section{Discussion}

An important modality for the assessment of the function of the testis is the measurement of its volume [1-5]. It is more challenging, however, to accurately measure the volume of smaller testes such as those of children or some men with infertility due to testicular failure, because of interference which may arise from the scrotal skin and tissues around the testis [18]. The Prader orchidometer is commonly used in the clinical assessment of testicular volume, due to its relative ease, low cost and reproducibility $[14,15]$. Some workers have shown that the orchidometer does overestimate the testicular volume measured, especially in small testes, as the scrotal skin, the epididymis and other peritesticular tissues are included in the measurement $[11,19,20]$. Testicular volume studies in an animal model using the orchidometer have shown that volume overestimations of up to $30 \%$

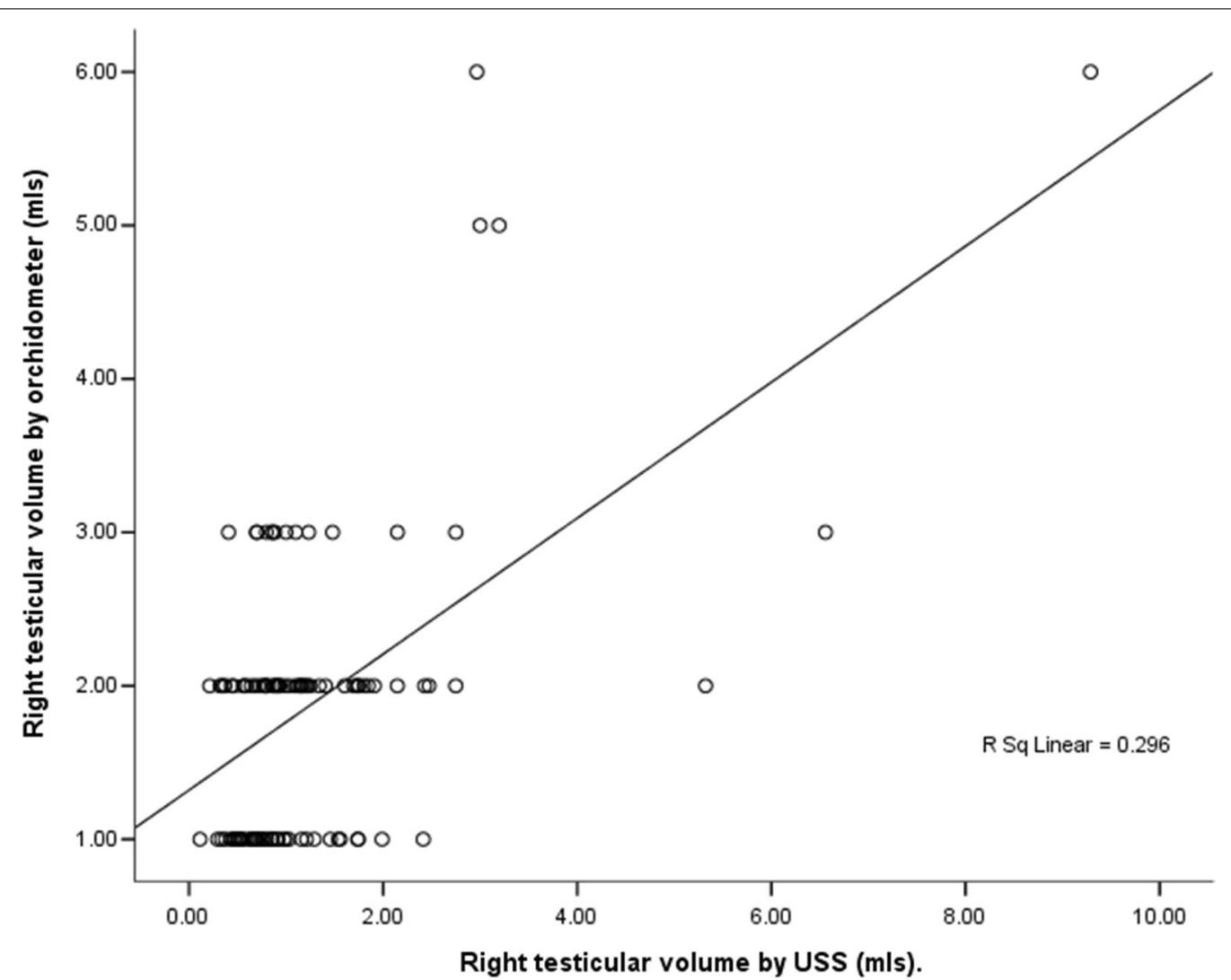

Fig. 1 Scatter plot of right testicular volume measurements by orchidometry and ultrasonography 


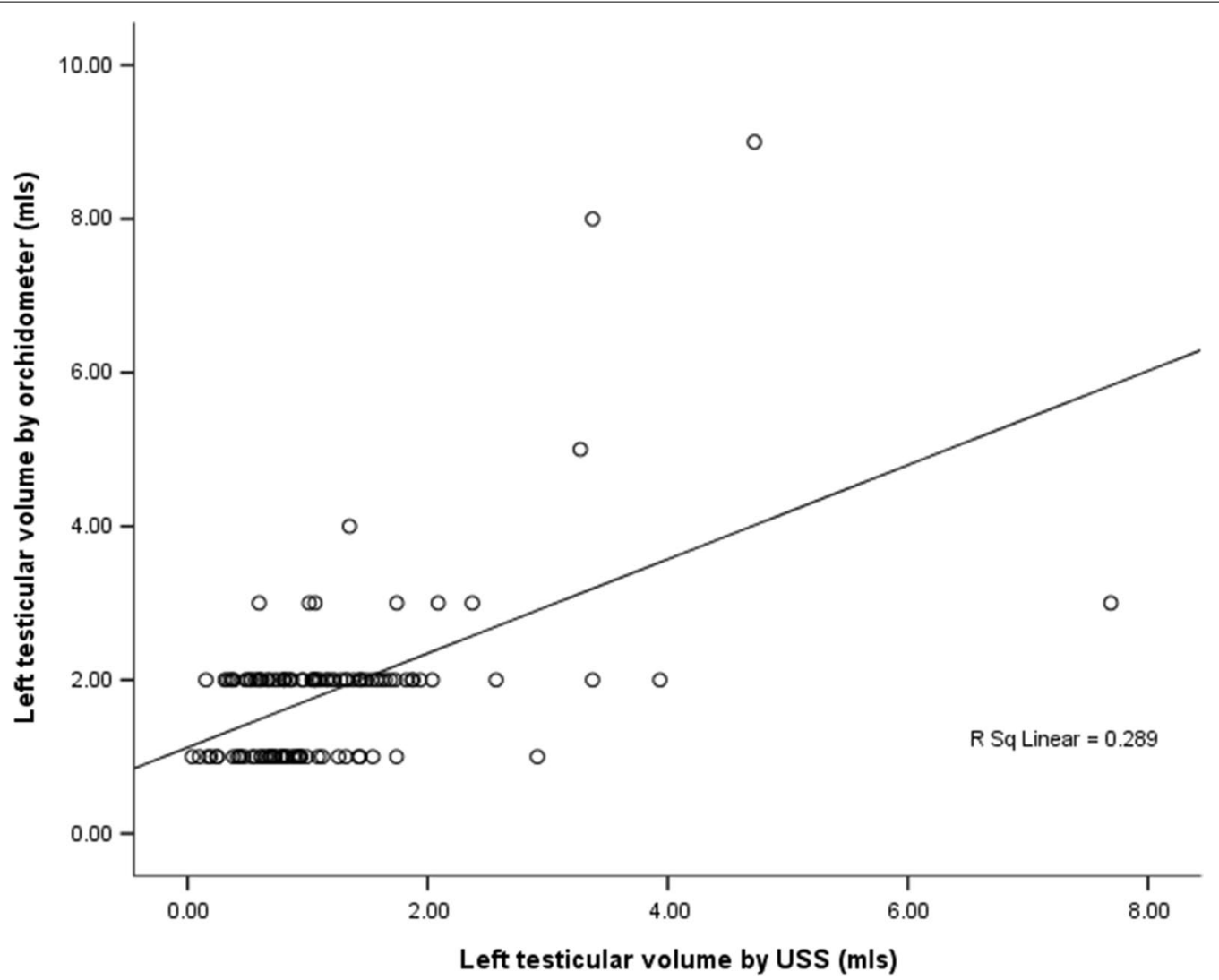

Fig. 2 Scatter plot of left testicular volume measurements by orchidometry and ultrasonography

may occur in testes whose actual volumes ranged from between 1 and $15 \mathrm{mls}$ [21]. The accuracy of testicular volume measured with the orchidometer has, however, been shown to be influenced by the observer's experience $[4,15,22]$. There is no consensus, however, on whether or not the reliability of the testicular volumes measured with the Prader orchidometer varies with the age of the subject [14]. Although the median age of the patients in this study was 3 years, their ages varied widely between 18 days and 13 years.

Although the method of testicular volume measurement judged to be the most accurate is still being debated, there are many who believe that ultrasonography (US) gives the most accurate in situ estimation of the volume of the testis $[4,12,13,18]$. It is commonly believed that US gives an excellent assessment of the volume of the testis which is reproducible, accurate and objective [23]. Testicular volume determination by US is calculated from measured parameters (Length[L], Width $[\mathrm{W}]$ and Height $[\mathrm{H}]$ ) of the testis gotten by using a high-frequency $(7.5 \mathrm{MHz})$ transducer to scan the testis in multiple planes $[1,4,12,13]$. The testis is believed to be an approximate ellipsoid, and its volume is thus calculated from inputting its measured parameters (Length, Width and Height) into various formulae $[1,12,13]$. In a study by Paltiel et al., which compared the testicular volumes gotten using various formulae (the formula for a prolate spheroid: $\mathrm{L} \times \mathrm{W}^{2} \times 0.52$; the formula for a prolate ellipsoid: $\mathrm{L} \times \mathrm{W} \times \mathrm{H} \times 0.52$; the Lambert empiric formula: $\mathrm{L} \times \mathrm{W} \times \mathrm{H} \times 0.71$ ) to that gotten by water displacement (true testicular volume) in a canine model, it was shown that the empiric formula of Lambert approximated most closely to the true testicular volume [13]. A study in human adults who underwent orchidectomy for the management of carcinoma of the prostate showed a similar result [16]. Lin et al., however, have shown in their study that the empiric formula of Lambert may not be the most accurate formula for the estimation of testicular volume in smaller testes [18]. All the volume calculations carried out in this present study employed the empiric formula of Lambert.

Ultrasound-measured testicular volume is dependent on the experience of the operator, as inter-observer and intra-observer variations have been reported [24]. Although it has fewer problems with soft tissue interference, the testes being elastic in nature and easily deformed by the applied transducer pressure could give a falsely larger length and a wider width during ultrasonography $[14,18]$. Also given that the testis is not perfectly an ellipsoid and that its shape is not regular, application 
of the ellipsoid formulae in its volume calculations may not yield an accurate figure [11]. Cha et al. showed that US underestimated testicular volume in children with statistical significance [25]. The similar results have also been reported in adults for the three commonly used US formulae for the calculation of testicular volume [16]. An additional advantage, however, in the use of US in testicular volume assessment is that it provides information on intrascrotal and intratesticular pathologies, thus making it complimentary to the orchidometer in testicular function assessment.

Various authors have shown in their studies that testicular volumes obtained using the orchidometer correlated well with volumes obtained using US and with the true testicular volume obtained by water displacement $[4,11-14,21,26,27]$. This present study also has shown that testicular volumes measured with the Prader orchidometer in children correlated significantly with volumes measured by US and with intra-operative caliper measurements. In this study, the testicular volumes estimated by the Prader orchidometer for both the left and the right testicles were significantly larger than those measured using US. This is, however, at variance with the findings of Tatsunami et al., who compared testicular volume measurements in adult (age range $20-26$ years) volunteers [22]. Intra-operative caliper-measured mean testicular volumes were lower than those measured by US and the orchidometer for both the right and left testes. This may be because the caliper measurements were only taken on the testes on the side of the pathology which may have affected the volumes. Adaletli et al. had earlier documented that flattening of the testes was noticed in $22 \%$ of children with hydrocoeles, and that $8 \%$ of them had testicular atrophy [28].

Also our data showed that for both US and orchidometer measurements, the right testicular volumes were larger than the left; however, there was no statistical significance. This may be explained by our small sample size [29]. Similar findings have been reported by other workers $[26,27]$. The observed difference between the volumes of the right and left testes may be explained by the more prominent pampiniform plexus and more sluggish venous drainage on the left side (due to the perpendicular drainage of the left testicular vein into the left renal vein) which results in a warmer and smaller ipsilateral testis $[20,27]$.

\section{Conclusions}

Our results show that testicular volumes measured with the Prader orchidometer correlated significantly with those measured by ultrasonography and intraoperative caliper measurements in children. The Prader orchidometer can thus be used in resource-constrained settings for a quick and reliable testicular volume assessment in children. Given that the testicular volumes measured with the orchidometer were significantly larger than those measured by ultrasonography in the present study, a clinical assessment of testicular volume in children using the Prader orchidometer is recommended in situations in which the absolute testicular volume is not required.

\section{Abbreviations}

MHz: MegaHertz; US: Ultrasonography.

\section{Acknowledgements \\ Not applicable. \\ Data from this study was presented at the 3rd World Congress of Pediatric Surgery. October 21-24, 2010 New Delhi, India.}

\section{Authors' contributions}

LCCA contributed to conception, data collection, literature review, data analysis and writing of main body of article and revised the article for scientific content; OAS and OA contributed to conception and literature review and revised the article for scientific content; CMA contributed to conception, data collection and literature review and revised the article for scientific content; MKS and AMM contributed literature review and revised the article for scientific content; MO, TAO and AOT contributed to data collection and literature review and revised the article for scientific content; and JBE contributed to data analysis and literature review and revised the article for scientific content. All authors have read and approved the manuscript.

\section{Funding}

This study received no funding or financial support.

\section{Availability of data and materials}

Data used in this study are available at: Anyanwu LJ. Testicular volume study dataset, Mendeley Data, v2; 2017. https://doi.org/10.17632/9vgrx75639.2.

\section{Ethics approval and consent to participate}

This study was approved by the Research Ethics Committee of the Obafemi Awolowo University Teaching Hospitals Complex Ile-Ife, Nigeria, on 11 January 2007; IRB/IEC Number of approval: 00005422 . For all patients included in this study, written informed consent was given by their parent or legal guardian.

\section{Consent for publication}

Not applicable.

\section{Competing interests}

None declared.

\section{Author details \\ ${ }^{1}$ Paediatric Surgery Unit, Department of Surgery, Obafemi Awolowo Univer- sity Teaching Hospitals Complex, Ife, Nigeria. ${ }^{2}$ Present Address: Paediatric Surgery Unit, Department of Surgery, Aminu Kano Teaching Hospital and Bay- ero University, Kano, Nigeria. ${ }^{3}$ Department of Radiology, Obafemi Awolowo University Teaching Hospitals Complex, Ife, Nigeria. ${ }^{4}$ Department of Radiol- ogy, Aminu Kano Teaching Hospital and Bayero University, Kano, Nigeria. ${ }^{5}$ Department of Paediatrics, Obafemi Awolowo University Teaching Hospitals Complex, Ife, Nigeria.}

Received: 30 December 2019 Accepted: 15 January 2020 Published online: 02 March 2020

\section{References}

1. Chipkevitch E, Nishimura RT, Tu DGS, Galea-Rojas M (1996) Clinical Measurement of testicular volume in adolescents: comparison of the reliability of 5 methods. J Urol 156:2050-2053 
2. Mul D, Fredriks MA, Van Buuren S, Oostdijk W, Verloove Vanhorick SP, Wit JM (2001) Pubertal development in the Netherlands 1965-1997. Pediatr Res 50:479-486

3. Cameron N, Grieve CA, Kruger A, Leschner KF (1993) Secondary sexual development in rural and urban South African black children. Ann Hum Biol 20:583-593

4. Schiff JD, Li PS, Goldstein M (2004) Correlation of ultrasonographic and orchidometer measurements of testis volume in adults. BJU Int 93:1015-1017

5. Arai T, Kitahara S, Horiuchi S, Sumi S, Yoshida K (1998) Relationship of testicular volume to semen profiles and serum hormone concentrations in infertile Japanese males. Int J Fertil Womens Med 43:40-47

6. Smyth CM, Bremner WJ (1998) Klinefelter Syndrome. Arch Intern Med 158:1309-1314

7. Flynn BJ, Myers SM, Cera PJ, Mowad JJ (2002) Testicular torsion in an adolescent with fragile X-syndrome. Pediatrics 109:e16

8. Niedzielski J, Pisarska K, Przewratil P (2003) The usefulness of testicular atrophy index in the assessment of undescended testicle. Preliminary report. Annals Academiae Medicae Bialostocensis 48:112-114

9. Yamamoto M, Hibi H, Katsuno S, Miyake K (1995) Effects of varicocelectomy on testis volume and semen parameters in adolescents: a randomized prospective study. Nagoya J Med Sci 58:127-132

10. Khan F, Muoka O, Watson GM (2011) Bell clapper testis, torsion, and detorsion: a case report. Case Rep Urol. https://doi.org/10.1155/2011/631970

11. Bhat S, Sathyanarayanaprasad M, Giridhar A, Srinivasa Y, Paul F (2016) Testicular volume measurement: comparison of Prader's orchidometry, ultrasonography, and actual volume by water displacement. J Integr Nephrol Androl 3:92-95

12. Diamond DA, Paltiel HJ, Dicanzio J, Zurakowski D, Bauer SB, Atala A et al (2000) Comparative assessment of pediatric testicular volume: orchidometer versus ultrasound. J Urol 164:1111-1114

13. Paltiel HJ, Diamond DA, Dicanzio J, Zurakowski D, Borer JG, Atala A (2002) Testicular volume: comparison of orchidometer and US measurements in dogs. Radiology 222:114-119

14. Goede J, Hack WWM, Sijstermans K, Van der Voort Doedens LM, Van der Ploeg T, Meij-de Vries A et al (2011) Normative values for testicular volume measured by ultrasonography in a normal population from infancy to adolescence. Horm Res Paediatr. https://doi.org/10.1159/00326057

15. Karaman MI, Kaya C, Caskurlu T, Guney S, Ergenekon E (2005) Measurement of pediatric testicular volume with Prader orchidometer: comparison of different hands. Pediatr Surg Int 21:517-520

16. Mbaeri TU, Orakwe JC, Nwofor AME, Oranusi CK, Mbonu OO (2013) Ultrasound measurements of testicular volume: comparing the three common formulas with the true testicular volume determined by water displacement. Afr J Urol 19:69-73

17. Lavoipierre AM (2000) Ultrasound of the prostate and testicles. World J Surg 24:198-207

18. Lin CC, Huang WJS, Chen KK (2009) Measurement of testicular volume in smaller testes: how accurate is the conventional orchidometer? J Androl 30:685-689

19. Chikani UN, Ibekwe MU, Chinawa JM, Adimora GN (2016) Testicular volume of healthy term neonates: Determination of normative values among Igbo babies in South-Eastern Nigeria. Niger J Clin Pract 19:85-90

20. Atalabi MO, Adeniji-Sofoluwe AT, Aremu IO (2015) Sonographic evaluation of testicular volume in neonates in Ibadan, Nigeria. J West Afr Coll Surg 5:41-59

21. Sakamoto H, Saito K, Oohta M, Inoue K, Ogawa Y, Yoshida H (2007) Testicular volume measurement: comparison of ultrasonography, orchidometry, and water displacement. Urology 69:152-157

22. Tatsunami S, Matsumiya K, Tsujimura A, Itoh N, Sasao T, Koh E et al (2006) Inter/intra investigator variation in orchidometric measurements of testicular volume by ten investigators from five institutions. Asian J Androl 8:373-378

23. Behre HM, Nashan D, Nieschlag E (1989) Objective measurement of testicular volume by ultrasonography: evaluation of the technique and comparison with orchidometer estimates. Int J Androl 12:395-403

24. Kujiper EAM, Van Kooten J, Verbeke JIML, Van Rooijen M, Lambalk CB (2008) Ultrasonographically measured testicular volumes in 0- to 6-yearold boys. Hum Reprod 23:792-796

25. Cha MH, Ahn BC, Kim YS (2006) Inaccuracy in ultrasonographic measurement of the testicular volume in children. Korean J Urol 47:866-869

26. Rundle AT, Sylvester PE (1962) Measurement of testicular volume. Its application to assessment of maturation, and its use in diagnosis of hypogonadism. Arch Dis Child 37:514-517

27. Kolade-Yunusa HO, Itanyi UD, Achonwa CJ (2017) Determination of a normogram for testicular volume measured by ultrasonography in a normal population boys in Abuja. Orient J Med 29:56-62

28. Adaletli I, Kurugoglu S, Kantarci F, Tireli GA, Yilmaz MH, Gulsen F et al (2006) Testicular volume before and after hydrocelectomy in children. J Ultrasound Med 25:1131-1136

29. Anyanwu LJ (2017) Testicular volume study dataset, Mendeley Data, v2. https://doi.org/10.17632/9vgrx75639.2

\section{Publisher's Note}

Springer Nature remains neutral with regard to jurisdictional claims in published maps and institutional affiliations.

\section{Submit your manuscript to a SpringerOpen ${ }^{\circ}$ journal and benefit from:}

- Convenient online submission

- Rigorous peer review

- Open access: articles freely available online

- High visibility within the field

Retaining the copyright to your article

Submit your next manuscript at springeropen.com 